\title{
PENGGUNAAN PINJAMAN MODAL KERJA PADA KOPERASI UNTUK PEMBERDAYAAN EKONOMI USAHA BATIK TULIS DI YOGYAKARTA
}

\author{
Kusuma Chandra Kirana \\ Universitas Sarjanawiyata Tamansiswa Yogyakarta \\ chandrakna@gmail.com
}

\begin{abstract}
The purpose of this study is to analyze the Influence of fund on Cooperatie to assist economic empowerment the Business of Batik Writing. The object of research are batik writing owner at district level in Yogyakarta Indonesia. Batik writing business that are members of Cooperatie sample are Yogyakarta City with 60 respondens. Type of data collected is of primary data and secondary data. Methods of data analysis used in this research include test validity, reliability test and regression analysis. Based on calculation of regression test to funding of capital variable is significant to economic empowerment on the business Batik Writing. Thus it can be concluded that the more effective use of capital loans made by the authors of batik then their economic independence is increasing. This means that the economic welfare of the managed batik business can be achieved.
\end{abstract}

Keywords: Capital Funding, Cooperatie, Economic Empowerment, Batik Writing.

\section{PENDAHULUHUAN}

Perkembangan industri batik cukup pesat di Indonesia, terdapat pusat-pusat sentra produksi yang menonjol di Indonesia, salah satunya yaitu Yogyakarta. Yogyakarta dikenal sebagai pusat industri dan pembelajaran batik terbesar di Indonesia. Pertumbuhan sektor industri batik di Yogyakarta secara tahunan mengalami peningkatan sebesar $20 \%$ per tahun dengan penyerapan tenaga kerja sebesar $2 \%$. Dari angka tersebut, diketehui bahwa industri batik tulis menyerap sekitar 600.000 tenaga kerja yang sebagian besar merupakan kaum perempuan, (Singgih Handoyo, 2017) Jumlah itu terus meningkat seiring perkembangan industri batik yang semakin baik. Banyak orang yang mulai bangga menggunakan batik sebagai busana sehari-hari. Oleh karena itu, batik tak hanya sebagai warisan budaya, tetapi juga mampu mengerakkan ekonomi masyarakat.

Yogyakarta merupakan kota dengan jumlah industri batik terbesar kedua di Indonesia. Berikut adalah tabel prosentase penyebaran jumlah industri batik tulis di Jawa tahun 2017: Dinas Perindustrian, Perdagangan dan Koperasi Daerah Istimewa Yogyakarta menyebutkan industri batik di daerah itu terus mengalami pertumbuhan dengan jumlah industri mencapai 3.000 IKM, meningkat dari 2013 yang berjumlah 2.980 IKM. Adapun sentra industri batik di DIY saat ini terdapat di Dusun Tancep, Trembowo (Kabupaten Gunungkidul), Imogiri, Pandak (Kabupaten Bantul), Sapon, Gulurejo, Lendah (Kulonprogo), Turi/lereng merapi (Kabupaten Sleman), dan Taman Sari (Kota Jogja). Untuk lebih jelasnya dapat dilihat pada tabel 1.

Berdasarkan tabel 1. Yogyakarta menempati $20 \%$ jumlah industri Batik tulis di bandingkan wilayah lain. Tingginya prosentase jumlah industri batik tulis di Yogyakarta menunjukkan bahwa Yogyakarta sampai saat ini masih menjadi salah satu pusat industri batik tulis di 
Indonesia. Industri batik tulis di Yogyakarta, merupakan industri dengan kategori Industri Kecil dan Menengah (IKM), yang dikelola oleh perorangan dan diwariskan secara turun temurun. Batik tulis menjadi salah satu industri garmen yang memiliki banyak peminat, tidak hanya di Indonesia, namun juga di Manca negara. Oleh karenanya, pengembangan industri batik tulis ini perlu terus dilakukan baik secara kualitas maupun kuantitas.

Upaya pengembangan industri Batik tulis, khususnya di Yogyakarta, terus berlanjut hingga saat ini. Namun, banyak para pengusaha batik tulis di Yogyakarta, yang terpaksa gulung tikar, dikarenakan kalah bersaing dengan batik imitasi (cap dan printing) yang nilai jualnya lebih murah, sehingga mampu menguasai pangsa pasar. Permasalahan utama pada industri batik tulis adalah, biaya produksi yang lebih mahal dibandingkan dengan batik imitasi. Tingginya kebutuhan modal untuk mengerjakan batik tulis, berpengaruh terhadap nilai jual produknya. Selain itu, peminat batik tulis yang tergolong ekslusif, (kelas menengah atas) menuntut kualitas yang tinggi, Sementara para pengusaha batik tulis di Yogyakarta, masih tergolong sebagai usaha rumahan dengan modal yang terbatas. Selain itu keterbatasan modal Kesulitan ,lainnya, yang masih dihadapi para pengusaha batik tulis di Yogyakarta, dikarenakan pengelolaan manajemennya yang masih sederhana. Lebih dari $50 \%$ para pengrajin batik tulis di Yogyakarta, mengalami keterbatasan modal. (Disperindagkop, 2017).

Keberadaan perbankan dan lembaga keuangan lainnya, menjadi tujuan utama para pengrajin dalam memenuhi kebutuhan modal. Namun, tidak semua pengrajin dapat mendapatkan modal dari perbankan, karena mereka tidak lolos secara administratif. Berkaitan dengan hal tersebut, banyak diantara para pengrajin batik tulis berkelompok untuk membentuk Koperasi simpan pinjam. Keberadaan Koperasi para pengrajin Batik ini, didirikan dalam rangka menjawab tantangan permodalan dari para pengrajin batik tulis di Yogyakarta.

Pola kerja koperasi sangat familiar di Indonesia, karena sesuai dengan karakter masyarakat Indonesia yaitu gotong royong dan kekeluargaan . Itulah sebabnya Koperasi menjadi dekat dengan hati masyarakat Indonesia. Sementara itu, Usaha Mikro Kecil dan Menengah (UMKM), yang tumbuh di Indonesia, khususnya diYogyakarta, amat diminati oleh masyarakat Indonesia. Hal ini terbukti dengan makin berkembangnya jumlah UMKM di Indonesia (Bela Fara,2016). UMKM juga memiliki peran strategis dalam upaya pengentasan kemiskinan. Pertumbuhan dan perkembangannya, tidak terlepas dari hubungannya dengan koperasi. Dengan demikian, IKM dan koperasi merupakan dua hal yang memiliki simbiosis mutualisme. Adapun model kerja koperasi dalam upayanya membantu permodalan bagi anggotanya, melalui pengelolaan dana bergulir.

Pengelolaan program pendanaanyang dikelola oleh koperasi untuk mendukung modal usaha penulisan batik agar operasinya bisa berjalan lancar. Kesulitan modal yang sering dialami pengusaha mikro, tidak dipenuhi oleh sistem perbankan. Kendala terbesar yang menghambat jalur komunikasi perbankan dengan pengusaha mikro adalah kelengkapan dokumen. Selain itu, sistem angsuran ketat dengan pembagian keuntungan pasti sering menjadi tekanan bagi pengusaha mikro. Dalam hal ini banyak pengusaha mikro mencari alternatif sumber modal dari perbankan. Dalam hal ini koperasi dipandang sebagai jawaban yang bisa membantu. Pentingnya peran koperasi dalam meningkatkan koperasi di Indonesia, mendorong peneliti melakukan penelitian yang bertujuan mencari jawaban dengan mencari model yang tepat. Model ini diharapkan dapat membantu pertumbuhan usaha batik tulis di Yogyakarta, melalui pinjaman modal kerja yang dikelola oleh koperasi. 


\section{HIPOTESIS}

Penelitian bertujuan ini mengajukan hipotesis penelitian yaitu :

H1. Penggunaan Pinjaman Modal Kemandirian. Ekonomi pengusaha batik tulis di Yogyakarta.

H2. Kemandirian Ekonomi berpengaruh signifikan pada Kesejahteraan pengusaha batik tulis di Yogyakarta

H3 Penggunaan Pinjaman Modal berpengaruh signifikan pada

Kesejahteraan Pengusaha batik tulis di Yogyakarta

\section{Model penelitian}

Kerangka konsep pada penelitian ini lebih lanjut dapat dilihat pada gambar berikut : tahun. (Zumario, 2017). Kredit modal kerja muncul karena banyak para wirausahawan yang masih memiliki modal minim untuk mengembangkan usahanya, maka kredil modal kerja pun bisa dijadikan pilihan agar bisnis yang dijalankan semakin besar. Fokus utama dari kredit modal kerja sendiri adalah untuk mendukung kemajuan usaha para calon peminjam dengan usaha kecil dan menengah agar mampu mengembangkan usaha mereka. Sehingga para wirausahawan yang memiliki usaha kecil dan menengah ini juga bisa melebarkan sayapnya supaya tidak tenggelam di dunia bisnis, yang mana seringkali terjadi bahwa bisnis kecil lambat laun akan tenggelam jika tidak segera dikembangkan. Seperti yang telah disebutkan di atas bahwa jangka waktu dari kredit modal

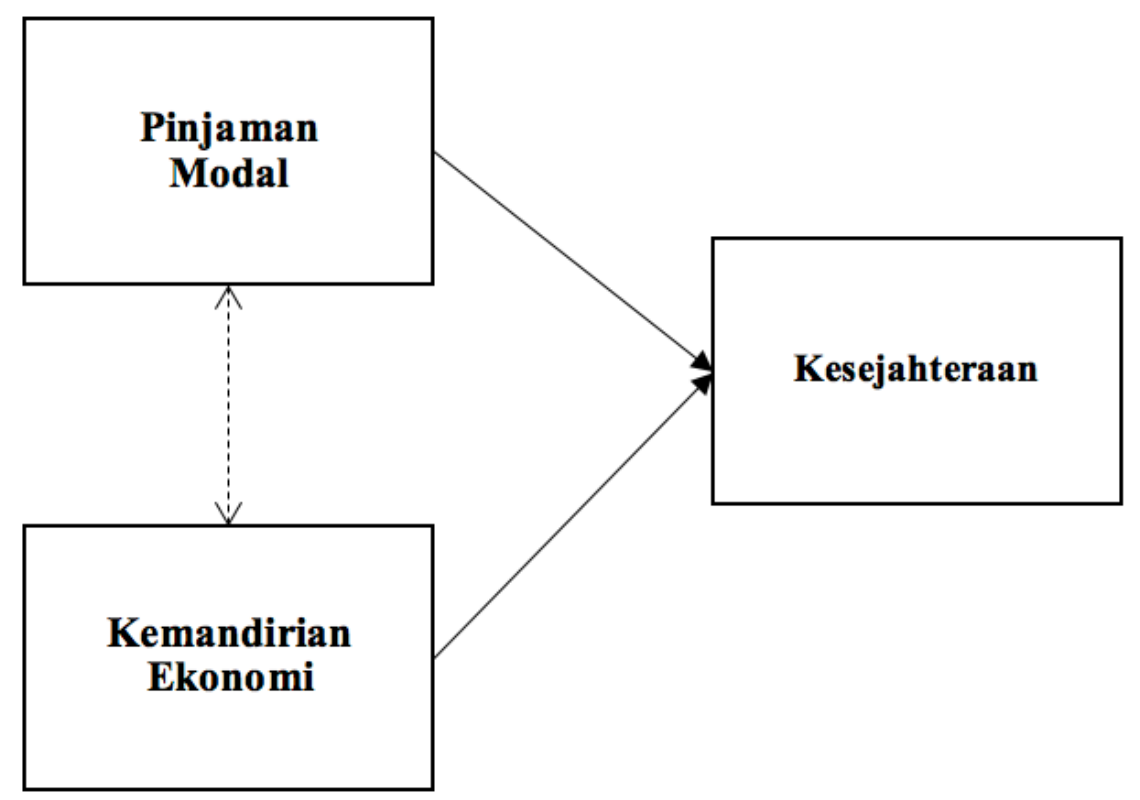

\section{Gambar 1}

Model Penelitian

\section{TINJAUAN PUSTAKA}

\section{Definisi Pinjaman Modal}

Kredit modal kerja ini merupakan kredit untuk perorangan atau sebuah badan usaha lainnya yang ingin mengembangkan lebih lebar usahanya dengan syarat sudah memiliki perijinan usaha dan usaha sudah berjalan selama kurang lebih satu kerja memang pendek, dengan patokan maksimal peminjaman hanya selama satu tahun. Dan dalam satu tahun tersebut nilai pencairan kredit maksimal $70 \%$ dari total kebutuhan modal kerja dengan jaminan usaha itu sendiri, sedangkan jaminan tambahan akan diikutsertakan apabila memang benarbenar dibutuhkan. 


\section{Definisi Koperasi}

Koperasi adalah suatu Lembaga sosial ekonomi yang dibentuk dalam rangka menolong diri sendiri atau bersamasama. Upaya ini dapat tumbuh dari dalam sekelompok masyarakat sendiri berkat munculnya kesadaran Bersama untuk pembefrdayaan diri, atau dapat pula ditumbuhkan dari luar kelompok masyarakat itu sebagai pemberdayaan oleh agents of development, baik pemerintah, maupun masyarakat, atau organisasi kemasyarakatan. (Swasono, 2017).

\section{Efektivitas Program Dana Bergulir Pada UMKM Untuk Pemberdayaan Ekonomi (Studi Pada Departemen Koperasi di Surabaya)}

Penelitian ini merupakan penelitian deskriptif dengan pendekatan kuantitatif. Lokasi penelitian di UKM dibantu oleh Departemen Koperasi yang mendapat dana bergulir. Populasi adalah penerima dana bergulir yang mencakup 50 UKM, teknik pengambilan sampel adalah probability sampling, jumlah sampel yang diambil ditentukan menurut Roscoe yang mencakup 30 UKM. Hanya ada satu variabel dalam penelitian ini, yaitu efektivitas program. Instrumen penelitian menggunakan keefektifan program oleh Danim (2004), yaitu jumlah hasil yang dapat dikeluarkan, tingkat kepuasan yang diperoleh, produk kreatif, dan intensitas yang akan dicapai. Metode pengumpulan data primer menggunakan kuesioner / kuesioner sedangkan data sekunder diperoleh dari studi kepustakaan. Efektivitas perhitungan dengan menggunakan uji validitas, reliabilitas efektifitas. Hasil penelitian menunjukkan bahwa efektivitas program dana bergulir untuk UKM dalam pemberdayaan ekonomi secara keseluruhan efektif.

Hasil penelitian menunjukkan bahwa efektivitas program dana bergulir untuk UKM dalam pemberdayaan ekonomi secara keseluruhan efektif. Dari uji validitas, reliabilitas dan kriteria efektif diperoleh bahwa masing-masing instrumen menunjukkan tingkat efektivitas yang signifikan. Langkah selanjutnya bagi pemerintah adalah mengoptimalkan lembaga penyaluran dana bergulir dan bersosialisasi bahwa status dana bergulir bukan merupakan dana gratis pemerintah.

\section{Sistem Evaluasi Dana Bergulir Untuk Departemen Koperasi Dan UKM di Surakarta}

Tujuan dari penelitian ini adalah untuk mengevaluasi pengelolaan program dana bergulir di Departemen Koperasi dan UKM di Surakarta dengan memperhatikan mekanisme pengelolaan kredit dana bergulir serta pro dan kontra dengan dana bergulir kredit. Mikro, kecil dan menengah sangat membutuhkan modal lebih untuk mengembangkan usahanya, agar bisa bersaing dengan UKM lainnya. Program penguatan permodalan untuk koperasi dan UKM di Surakarta mempengaruhi perkembangan usaha mikro, kecil dan menengah, karena persaingan dan kebutuhan modal yang ketat untuk menjalankan pengembangan usaha. Suku bunga rendah dan jangka waktu yang panjang dapat meringankan pelaku usaha mikro, kecil dan menengah. Hasil penelitian ini menunjukkan bahwa program dana bergulir belum memuaskan. Kesimpulan dari penelitian ini adalah bahwa program dana bergulir kurang efektif dan efisien. Berdasarkan penelitian ini, penulis menyarankan agar program dana bergulir harus dievaluasi dan kekurangannya harus ditingkatkan, mengingat program kredit dana bergulir tidak menghasilkan keuntungan dan bahkan mengalami kerugian.

\section{Analisis Dampak Kebijakan Penyaluran Kreditr Kepada UMKM Terhadap Pertumbuhan Pembiayaan UMKM oleh Perbankan.}

Berdasarkan Peraturan $\mathrm{BI}$ no. 14, ditetapkan bahwa bank umum wajib menyalurkan $20 \%$ dari total kreditnya 
untuk pengembangan UMKM. Dengan adanya aturan ini diharapkan dapat memacu pertumbuhan UMKM di Indonesia. Berdasarkan penekitian dari Caerani Nisa, ditemukan bahwa penyaluran kebijakan tersebut tidak berdampak signifikan terhadap pertumbuhan UMKM di Indonesia. Adapun kendala ketidakefektifan yang terjadi adalah berada pada pelaku usaha (pengusaha UMKM) sendiri, yang kurang fokus terhadap alokasi penggunaan modal kredit yang mereka dapatkan.

\section{Metode Penelitian}

Penelitian ini menggunakan pendekatan, kuantitatif, yang dianalisis dengan menggunakan analisis regresi. Analisis regresi digunakan untuk mengetahui tingkat pengaruh penggunaan modal kerja terhadap pemberdayaan ekonomi pada pengusaha batik tulis di Yogyakarta. Lokasi penelitian ini adalah kota Yogyakarta, dengan populasi penelitiannya adalah para pengusaha batik tulis yang terkategori Industri Kecil Menengah (IKM). Sampel penelitian berjumlah 60 orang yang sudah mendapatkan modal kerja dari koperasi. Waktju penelitian kurang lebih 1 bulan yang dimulai pada awal bulan Januari 2018 .

\section{Analisis Dan Pembahasan}

Pada awalnya koperasi merupakan unit usaha Bank Perkreditan Rakyat (BPR). Dari pertumbuhan koperasi sebagai mitra ekonomi mikro, dan mulai berperan penting dalam memperkuat ekonomi masyarakat akar rumput di Indonesia. Proses operasional yang sederhana dan dekat dengan orang miskin, menjadikan koperasi memiliki peran besar dalam pengembangan bisnis penulisan batik di Yogyakarta. Usaha Mikro Kecil Menengah, merupakan bisnis yang berkembang pesat di Indonesia, khususnya di Yogyakarta. Jenis usaha yang banyak diminati di kelompok UKM adalah industri batik. Perkembangan industri batik di Yogyakarta terus meningkat dalam 3 tahun terakhir. Pada tahun 2017, industri batik di Jawa Tengah mencapai 10\%. (Disperindagkop,2017). Ini berarti pangsa pasar Batik masih melebar. Tingginya permintaan Batik baik dari masyarakat Indonesia maupun negara anoyher, turut berperan dalam perkembangan industri batik. Sebelum koperasi dikenal di Komunitas, pengusaha batik mencari pinjaman modal usaha melalui perbankan, namun karena prosesnya yang lamban dan agak rumit, beberapa pengusaha batik memilih mencari modal untuk perorangan. Jenis pinjaman ini, seringkali biaya tinggi dan tingkat suku bunga, berdampak pada berkurangnya pendapatan usaha.

Koperasi Batik tumbuh di Indonesia pada 1990-an, fokus usaha koperasi adalah memberikan pinjaman modal jangka pendek pada pengrajin batik. Proses pelayanan yang cepat dengan sistem yang sederhana, menjadi pilihan utama pengusaha batik untuk memenuhi kebutuhan modal. Dalam operasionalnya, Koperasi menggunakan model Dana Bergulir, dalam memberikan pinjaman modal. Dana bergulir adalah, dana yang disediakan untuk memenuhi kebutuhan modal anggota koperasi, yang masa pembayarannya kurang dari 3 bulan. Besarnya kompensasi atau biaya yang dikenakan pada modal pinjaman, tidak lebih dari $1 \%$, Selain biaya penyaluran modal yang rendah, proses pemberian dana bergulir yang mudah dan tanpa jaminan membuat pengusaha memilih dana bergulir untuk memenuhi kebutuhan modal jangka pendek.

\section{Hasil Pembuktian Hipotesis}

Berdasarkan hasil analisa validitas untuk masing - masing - masing indikator, diketahui bahwa data dinyatakan valid. Sedangkan uji reliabilitas menunjukkan data Reliabel, dengan demikian dapat dilakukan proses analisis data dengan menggunakan teknik analisis regresi. Adapun hasil uji vaditas variable penelitian, secara lebih jelas dapat dilihat pada tabel 2 berikut :

Tabel 2 


\section{Hasil Analisis Regresi Berganda \\ Pengaruh Pinjaman Modal terhadap Kemandirian dan kesejahteraan pengusaha Batik Tulis di Yogyakarta}

\begin{tabular}{cccc}
\hline Variabel & $\beta$ & $\mathrm{t}$-value & $\mathrm{p}$-value \\
\hline Constant & $-0,125$ & $-0,556$ & 0,541 \\
Peinjaman Modal & 0,039 & 0,745 & 0,001 \\
Kemandirian Ekonomi & 0,027 & 3,548 & 0,000 \\
Kesejahteraan & 0,009 & 0,653 & 0,427 \\
& & & \\
& & & \\
\hline Adjusted R Square (R2) & 0,445 & \\
F-value & 3,204 & \\
p-value & $0,009^{*}$ \\
\hline \multirow{2}{*}{ * Significant at a $=0,05$} \\
\end{tabular}

Sumber: Hasil olah data primer

\section{PEMBAHASAN}

Berdasarkan Hasil penelitian, maka di ketahui bahwa hampir semua pengusaha IKM Batik Tulis , di Yogyakarta, merasakan dampak positif dengan adanya penggunaan Modal Kerja yang dikelola oleh Koperasi.
Hasil analisis deskriptif pada responden terpilih, secara lebih lengkap dapat dilihat pada tebel dibawah.

Berdasarkan data yang diperoleh sebesar $35 \%$ pengrajin batik yang menggunakan Modal Kerja melalui Koperasi di Yogya-

Tabel 3

Karakteristik Responden berdasarkan Jenis Kelamin

\begin{tabular}{lcc}
\hline Keterangan & Jumlah & Prosentase \\
\hline Laki-laki & 21 & $35 \%$ \\
\hline Perempuan & 39 & $65 \%$ \\
\hline Total & 60 & $100 \%$ \\
\hline
\end{tabular}

Sumber : Data Penelitian

Tabel 4

Karakteristik Responden berdasarkan Pendidikan Terakhir

\begin{tabular}{lcc}
\hline Keterangan & Jumlah & Prosentase \\
\hline SD & 6 & $10 \%$ \\
\hline SMP & 14 & $23 \%$ \\
\hline SMA & 33 & $56 \%$ \\
\hline Diploma & 2 & $3 \%$ \\
\hline Sarjana & 5 & $6 \%$ \\
\hline Total & 60 & $100 \%$ \\
\hline
\end{tabular}

Sumber : Data Penelitian 
karta adalah laki-laki, sedang sebesar $65 \%$ adalah perempuan.

Berdasarkan data yang diperoleh sebesar $10 \%$ pengusaha IKM batik tulis yang menggunakan Modal Kerja melalui Koperasi di Yogyakarta berpendidikan terakhir SD, dan sebesar $23 \%$ berpendidikan terakhir SMP, sebesar $56 \%$ berpendidikan terakhir SMA, sebesar $3 \%$ berpendidikan terakhir Diploma serta sebesar $6 \%$ berpendidikan terakhir Sarjana.

\section{SIMPULAN}

\section{Penggunaan Modal Kerja berpengaruh terhadap Kemandirian Ekonomi IKM Batik Tulis di Yogyakarta}

Berdasarkan hasil analisis diperoleh nilai signifikansi Penggunaan Modal Kerja adalah 0,001, hal ini berarti bahwa penggunaan modal kerja berpengaruh terhadap Kemandirian Ekonomi Pengusaha Batik Tulis di Yogyakarta. Nilai ini masih dibawah 0,050, sehingga dinyatakan bahwa Penggunaan Modal Kerja berpengaruh terhadap kemandirian ekonomiPengusaha Batik Tulis di Yogyakarta. Berdasarkan hasil analisis diperoleh nilai signifikansi Kemandirian Ekonomi berpengaruh terhadap Kesejahteraan Pengusaha Batik Tulis adalah 0,000 . Nilai ini masih dibawah 0,050, sehingga dinyatakan bahwa Kemandirian Ekonomi berpengaruh terhadap Kesejahteraan Kesejahteraan Pengusaha Batik Tulis di Yogyakarta.

Pemilik IKM Batik Tulis merasakan Peningkatan Kesejahteraan dan mendapatkan manfaat positif dengan pemanfaatan Modal Kerja pada Koperasi di Yogyakarta. Namun, para pengurus Koperasi perlu memperhatikan keluhan para pengusaha IKM Batik Tulis yang menjadi nasabahnya, karena bisa berakibat kurangnya kepercayaan terhadap Koperasi, yaitu masalah ketersediaan dana sesuai kebutuhan sehingga nasabah tidak harus mencari di tempat lain.

\section{Kemandirian Ekonomi berpengaruh terhadap Kesejahteraan IKM Batik Tulis Melalui Koperasi di Yogyakarta}

Berdasarkan hasil analisis diperoleh nilai signifikansi Kemandirian Ekonomi berpengaruh terhadap Kesejahteraan IKM Batik Tulis di Yogyakarta adalah 0,000 . Nilai ini dibawah 0,050 , sehingga dinyatakan bahwa Kemandirian Ekonomi berpengaruh terhadap Kesejahteraan IKM Batik Tulis di Yogyakarta. Berdasarkan hasil analisis diperoleh nilai signifikansi Penggunaan Modal kerja berpengaruh terhadap Kesejahteraan IKM Batik Tulis di Yogyakarta adalah 0,427 . Nilai ini diatas 0,050 , sehingga dinyatakan bahwa Penggunaan Modal Kerja tidak berpengaruh terhadap Kesejahteraan IKM Batik Tulis di Yogyakarta.

\section{Penggunaan Modal Kerja berpengaruh terhadap Kesejahteraan IKM Batik Tulis di Yogyakarta}

Berdasarkan hasil analisis diperoleh nilai signifikansi Penggunaan Modal Kerja berpengaruh terhadap Kesejahteraan IKM Batik Tulis di Yogyakarta adalah 0,427 . Nilai ini diatas 0,050 , sehingga dinyatakan bahwa Penggunaan Modal kerja tidak berpengaruh secara langsung terhadap Kesejahteraan IKM Batik Tulis di Yogyakarta, namun Penggunaan modal kerja akan berpengaruh terhadap Kesejahteraan jika melalui variabel antara yaitu kemandirian ekonomi.

Saran yang diperlukan agar penelitian ini berjalan dengan baik adalah : Bagi pihak Pengurus Koperasi, sebaiknya perlu memperhatikan keluhan nasabah, diantaranya adalah : administrasi kurang puas, lelet, sehingga perlu ditingkatkan lagi, ketersediaan dana kurang jelas, masjid kurang besar sehingga tidak ada tempat untuk sholat jumat.

Bagi penelitian selanjutnya, perlu dilakukan penelitian dengan memasukkan variabel tingkat kelancaran penyaluran dana sebagai variabel moderator. 


\section{DAFTAR PUSTAKA}

Arikunto, S. 2006. Research Procedures A Practice ApproachPT Renika Cipta. Jakarta.

Chandra Kirana, Kusuma \& Ririn Triratnasari. 2017. BMT Empowerment Through Revolving Fund Patterns on Micro Finance. Jakarta : Book Program ICIED 2017.

Farida, Idah. 2011. Effectiveness of Sharia Revolving Fund Program for Improving KJKS / BMT Financial Access In order to Strengthen SMEs. Skripsi. Jakarta. UIN-Syarih Hidayatullah.

Firdaus, Muhammad, Muhammad Aziz Hakim, Sofiniyah Ghifron, dan Mukhtar Alshodiq. 2005. Dasar dan Strategi Pemasaran Syariah. Penerbit Renaisans. Jakarta.

Indiana, Bela fara. 2016. Evaluation of Revolving Fund System for SMEs at the Department of Cooperatives and SMEs Surakarta. Tesis. Program Pascasarjana Universitas Sebelas Maret Surakarta

Kristianto, Johan,. 2013. The Effectiveness of Revolving Fund Programs for SMEs in Economic Empowerment (Study on SMEs Bureau Dinas Koperasi, Kota Surabaya).

E-Journal. Unesa. Publika. Vol.1 No. 2

Pandriadi, et all. 2015. The Role of Islamic Microfinance on Alleviating Poverty in Developing Countries. Book Program ICIEF'2015. P. 43. .

Shemwell, Donald J., Ugur Yavas, and Zeyneb Bilgin. 1998. Customer-Service Provider Relationships : An Empirical Test of A Model of Service Quality, Satisfaction, and Relationship-Orientef Outcomes. International Journal of Service Industry Management. Vol. 9. No. 2. pp. 155-168.

Silverhart, Todd A. 2004. A Question of Trust. LIMRA's Marketfacts Quarterly. Winter. Vol. 23. No. 1.

Solimun. 2002. Structural Equation Modelling Lisrel dan Amos. Fakultas MIPA Universitas Brawijaya. Malang.

Yumna, Alimatul dan Sany Dwita.2015. Keys Success Factors and Challenges in Managing a Baitul Maal : A case Study of Baitul Maal Beringharjo Yogyakarta. Buku Program. International Call For Paper, ICIEF'2015. P. 3 